\title{
Carta abierta sobre la "Vocación temporal"
}

Esta carta abierta, en la que no faltarán algunas repeticiones, va dirigida a todos los que han leído nuestro artículo "Teología de la vocación religiosa", publicado en Estudio Agustiniano 3 (1968) 505-526, y en Todos Uno, nov.-dic. 1968, enero-febrera 1969. Quiere ser al mismo tiempo un diálogo-respuesta con todos los que nos han formulado, de palabra o por escrito, sus dudas u objeciones. Es claro que no podemos volver a repetir aquí todo el artículo, calificado por algunos profesores de universidad como "equilibrado y de centro" ante la oposición de cientos "inquisidores" a que se ppublicara. Cfr. Todos Uno, n. 14, marzoabril 1969, pp. 140-141. Esta calificación debería ser ya por sí sola una llamada de atención a los demasiado esarupulosos, que ven espejismos por doquier. Para mayor claridad, será conveniente hacer algunas divisiones.

\section{ES UN PROBLEMA TEOLÓGICO.}

El artículo en cuestión trata únicamente de dar una explicación teológica a un hecho o praxis de la Iglesia, que nadie puede negar ni dejar de tomar en serio. A un teólogo experimentado le bastaría esta constatación inicial del artículo para no ver peligros ni desviaciones doctrinales o prácticas en donde no las hay. Porque, siendo la vida religiosa un "lugar teológico" o fuente de doctrina teológica, la praxis de la Iglesia sirve de fundamento a la explicación teológica, y no viceversa. Es éste el principio más elemental de toda metodología teológica, cuando se analizan los elementos o los caracteres de las instituciones cristianas. Será preciso poner algún ejemplo que lo aclare.

Si la Iglesia admite algunos sustitutos del bautismo de agua, en teología esto quiere decir que el bautismo de agua no es ya absolutamente necesario para da salvación. Si ha habido bautismos administrados "en nombre de Jesús" y han sido reconocidos como válidos por la Iglesia, en teología esto quiere decir que la fórmula trinitaria no es absolutamente necesaria para la validez del bautismo. Si se prueba históricamente que algún simple presbítero (abad, o no) ha realizado alguna consagración episcopal, reconocida como válida por el Papa, en teología esto quiere decir que no es absolutamente necesario para la validez de la consa- 
gración episcopal un ministro nevestido del sacerdocio episcoppal. Del mismo modo, si la Iglesia dispensa de los votos a algunos religiosos o religiosas por diversas razones y sin mirar a los pocos o muchos años de vida consagrada que hayan vivido, en teología esto quiere decir simplemente que esas personas cambian legítimamente de estado, y no que antes no han tenido vocación. Hay quienes se asustan de que a esto lo llamemos "vocación temporal", como si con ello peligrara el valor y la seriedad de las vocaciones perpetuas. Sin embargo, si atendemos a la praxis de la Iglesia, no veo por qué las almas piadosas han de echanse a temblar. Basta tener un concepto dlaro de lo "oscura" que suele ser en la práctica la vocación religiosa, para no ver en ella "un seguro de vida", sino simplemente un camina cristiano de perfección. A continuación trataremos de ir matizando todo esto, con la esperanza de que la realidad se imponga a una cierta especulativización bastante apersonal y rígida.

\section{LA VOCACIÓN RELIGIOSA.}

Ed Vaticano II nos dice que la vida religiosa es un medio para conseguir la perfección cristiana, cuya esencia consiste en la caridad. No repetiremos aquí las citas del artículo. Pero parece que es necesario insistir en que los votos religiosos, en su forma actual, proceden únicamente de la disciplina eclesiástica. Las Reglas más primitivas, como la de San Agustín, no hablan para nada de los votos, porque tenían de ellos un concepto muy distinto del nuestro. El votum significaba para ellos promesa, propósito u ofrenda personal, y por lo mismo apenas había procedimientos canónicos ni para la admisión ni para la expulsión o el abandono voluntario de los monjes. Todo se dejaba a la responsabilidad comunitaria, y sobre todo a la individual, de la que sólo Dios puede juzgar con justicia y verdad.

El concepto de vocación religiosa lo hemos expuesto brevemente en el articula Todas y cada una de las vocaciones al servicio de la única misión de la Iglesia, en Todos Uno, n. 14, marzo-abril 1969, 81-115. ver pp. 107-108. El Vaticano II nos dice que es un don o una llamada de Dios, y habla de los gérmenes de la vocación, con tal que esto no se entienda en un sentido determinista a ultranza. Nos dice también que esa vocación no suele manifestarse de una forma extraordinaria. Por eso, de ordinanio, para probar en la práctica esa vocación contamos únicamente con ciertos datos subjetivos probables y oon la aprobación de la jerarquía. Como en todo lo que se refiere a la economía de la gracia, también aquí nos vemos sujetos en los casos ooncretos a la probabilidad y a las limitaciones humanas. Claro que la vocación religiosa, o mejor, la profesión, es un compromiso personal, y muy serio, ratificado por la Iglesia; y que de por sí tiende a la perennidad, como todos los carismas. Eso ya quedó bien 
olaro en el antícula en cuestión. Pero es un compromiso humano con todo lo que esto implica de condicionado e imprevisible. Por eso, ouando la Iglesia dispensa a alguien de los votos, temporales, perpetuos o solemnes, no dice que ese religioso no ha tenido nunca vocaciún, sino que se limita a aconsejarle; (permitirle o exigirle la secularización por las razones que juzga oportunas. El númerio de los casos no importa para que esta praxis de la Iglesia esté pidiendo una explicación teológica. Negar el valor a esta praxis de la Iglesia, sería negarle, oon Lutero, la potestad de institucionalización de la vida religiosa; y considerar esas dispensas como una quimera o un mal menor, sería no tomar en serio a la misma Iglesia. ¿Es que la dispensa indica quie Dios y la Iglesia se equivocaron de plano al admitir a algunos a la pirofesión religiosa, o que los dispensados son necesariamente culpables de infidelidad a sus promesas? No creo que nadie se atreva a responder afirmativamente a estas preguntas, si no quiere constituirse en juez de Dios, de la Iglesia y de las conciencias ajenas. Por lo visto y aunque lo hagan inconscientemente, !parece ser que no todos se ven libres de esta presunción tan peligrosa. Aunque volveremos a insistir en este punto, pasemos por ahora a la explicación propiamente teológica de la praxis de la Iglesia.

\section{LA EXPLICACIÓN TEOLÓGICA.}

Partiendo de que la vocación religiosa es un medio para alcanzar la perfección cristiana, según nos lo enseña el Vaticano II, es claro que se trata de una gracia accidental con respecto a la salvación eterna. Por eso hemos enfocado toda el problema a la luz de la doctrina católica sobre la gracia. Gracia y natzoraleza: he ahí, a nuestro modo de ver, la clave para dar una explicación teológica al problema que nos ocupa. $Y$, sin embargo, los que ponen reparos a la iposible vocación temporal no hacen ninguna referencia seria a esto, y dan la impresión de que no captan su importancia en la concepción cristiana de la antrotología. Los que conozcan un poco las tesis fundamentales de la escuela aqustiniana y las obras histórico-teológicas, por ejemplo, del P. H. De Lubac, saben muy bien lo que significan en el momento presente para la teología cristiana, sobre todo si, además, oonocen los postulados de la psicología moderna. La gracia no es ningún talismán incrustado en el hierro frío de una naturaleza inmóvil, y Dios no es ningún orfebre que se deje prender desde fuera $y$ a oios vistas jpor las mallas de nuestra temporalidad irremediable, que auiere siempre "jugar a reternidad". $\mathrm{Y}$ no podemos seguir barajando la omnisciencia divina, aue conoce todos los vai. venes de nuestra vida, como si eso fuera una solución al problema de la iplerennidad de la vocación; porque se da el caso de que nosotros no gozamos de esa omnisciencia y por lo tanto tenemos que atenernos a la realidad que nos rodea. 
En nuestro artículo tratábamos también de desdramatizar la situación penosa en que suelen encontrarse los que abandonan la vida religiosa, aun cuando lo hacen como es debido: consultas al confesor, a los superiores, al psiquiatra, permiso de la Santa Sede. Por eso, todas las consideraciones ascéticas, nacidas con frecuencia de la incomprensión y del método nefasto de la desconfianza para toda situación ajena, pueden tener aplicación en algunos casos y se dan ya por supuestas, pero no explican en absoluto el problema teológico que nos ocupa. Panece como si la vocación religiosa fuera para estos jueces una especie de órgano suplementario, que sólo puede ser amputado por la infidelidad a Dios y a sf mismo.

Todos estamos de acuerdo en que sin la intención inicial de perennidad no puede haber votos religiosos solemnes o perpetuos; pero, de hecho, la realidad de la vida y la praxis de la Iglesia están ahí para enseñarnos que nuestra ansia de "un seguro de vida" y de eternidad de todo lo que hacemos se quiebra contra la temporalidad, por ahora incurable, de nuestra condición humana y de todo lo que nos concierne. De esto nos dan unas lecciones tremendas los mismos teólogos de la "teología radical" y los filósofos modernos, incluso los socializantes ateos como Marcuse, además de los psicólogos, al interpretar en este sentido ciertos mitos griegos. Esto lo sabe muy bien la Iglesia, y hoy más que nunca, al redescubrir su "escatologismo" esencial, porque vive en medio del mundo, y los nuevos hallazgos de la antropología y de la psicología modernas la ayudan a captar muchos misterios humanos que antes nadie conocía. Por eso, una de las cosas que más pesan en Roma para dispensar los votos religiosos o el celibato eclesiástico es precisamente el dictamen del psiquiatra. No creo que hoy día se atreva ya nadie a repetir en serio la frase que algunos atribuyen a un monseñor romano, al enviar hace años una dispensa de votos solemnes: "Ahí va un pasaporte para el infierno". ippara que luego se extrañe uno de que los ateos nos acusen de haber juzgado durante mucho tiempo a la divinización del hombre! $\mathrm{Y}$, ¿quién puede comprender hoy día dentro de un marco cristiano serio el que se haya defendido que es preferible ir a dar con sus huesos al manicomio (ahora lo llaman por finura "clínica psiquiátrica"), antes que abandonar la vida neligiosa?

El Vaticano II nos está gritando quie han cambiado muchas cosas en el mundo actual, y que es previso respetar al hombre. Por eso, ha cesado esa legislación rígida en muchas cosas; sobre todo cuando lo que está en juego no es la salvación eterna, sino sólo un medio, excelente, pero un medio, para conseguir la pro. pia perfección cristiana y ayudar a los demás a conseguirla. Si ese medio se convierte en un obstáculo, por causas "hic et nunc" razonables, díganme si es preferible seguir dando consejos inútiles "de ascética y mística". Es claro que debe haber causas justas para abandonar la vida religiosa o el celibato sacerdotal, y 
así lo exige la praxis de la Iglesia. En el aftículo no hicimos más que mencionar algunas de esas causas, que suelen figurar en los documentos pirivados de las dispensaș. Pero, si hiciéramos un breve recorrido por la historia de la vida religiosa, veríamos que los casos de "vocación temporal" son mucho más frecuentes die lo que generalmente se piensa. Aparte de la sulpresión oficial de algunas ónde. nes religiosas, como la de los templarios, y de varios monasterios, bastaría recordar aquí lo que sucedió después de la exclaustración española diel siglo pasado. La mayor parte de los religiosos sacerdotes pasaron all clero secular; pero ¿cuántos volvieron a los conventos cuando comenzaron a restaurarse las provincias religiosas? Por citar un ejemplo: de los varios centenares de religiosos de una orden bien conocida no volvió ninguno, ni siquiera el que desempeñaba entonces el cargo de Comisario General. Muchos ofrecieron su ayuda económica, y eso fue todo. Ahora pregunto a los que se escandalizan de la "vocación temporal" por otras causas personales o ambientales mucho más graves: ¿Es que todos esos religiosos, algunos de ellos ya bien veteranos, habían vivido en los conventos sin vocación?

Es nedesario juzgar las cosas oon serenidad y sin precipitarse. ¿Dónde está la teología y el Vaticano II? Nadie sabe, a no sar por una revelación especial, si tiene la gracia habitraal, que es del todo necesaria para la salvación (Conc. de Trento), ¿y se pretende sin más saber con certeza que se posee la vacación perenne, que es sólo un medio parara la perfección? Cuando la experiencia prudencial demuestra que la vida religiosa se ha conventido en un obstáculo para la perfección de alguno o algunos religiosos, y la jerarquía lo confirma con su aprobación, se realiza exactamente lo contrario de lo oue sucediớ en la admisión del candidato a la lprofesión, pero no se destruye ni el tiempo pasado ni los planes de Dios sobre cada persona. $Y$ sulpongo que nadie osará entonces ir a buscar en la Sagrada Escritura ciertos textos bíblicos que corroboren la perennidad de la vocación religiosa, cuando allí se habla de la fidelidad al cristianismo o del cumplimiento de ciertas promesas |pesajeras!

Algunos tienden a comparar la profesión religiosa con el matrimonio cristiano, como si se tratara de un compromiso semejante. Por este camino se llega precisamente a todo lo contrario de lo que ellos pretenden. Además de que el matrimonio cristiano es un sacramento y la profesión religiosa no lo es, la praxis misma del anulamiento del matrimonio rato y no consumado, aue puiede $\mathrm{mn}$. ceder el Papa, quiere decir para el teólogo que en ciertos casos la indisolubilidad del matrimonio cristano está encomendada a la admnistración de la Iglesia. No quiero recordar aquí las consecuencias que comienzan ya a sacar de esa praxis algunos teólogos en sus escritos y al.gunos obispos de ciertas regiones en la toráctica. ¡Más estudio, purues, de la teologla y de la historia de la Iglesia, y menos devocionarios que fomentan el "escándalo de los pusilánimes"! ¿Es que la ver- 
dad desnuda puede perjudicar la tarea de los formadores? Todo lo contrario. Eso debe enseñar a todos que en el cristianismo no hay ni puede haber "seguros de vida", que es preciso austodiar con esmero los dones que creemos haber recibido de Dios y vivir siempre alerta, y que en conformidad con el escatologismo bîblico y con nuestra condición humana tiene muha razón San Agustín cuando, refiriéndose precisamente a los monjes, afirma con el Eclesiástico $(11,30)$ : "Por el momento no alabes con seguridad vida alguna: antes de la muerte no alabes a hombre alguno" (In P. 99, 11, PL 37, 277).

El que, a pesar de todo, prefiera seguir considerando a toda vocación religiosa como una entelequia bajada del cielo, clara, segura y perenne, contra lo que nos enseñan la realidad y la praxis de la Iglesia, allá él!

A. TURRADO 